\title{
Knowledge of Obstetric Danger Signs Among Women of Reproductive Age in Rural Communities in Enugu State, Nigeria
}

\author{
Chuka C. Agunwa ${ }^{1}$, Chinomnso C. Nnebue ${ }^{2}$, Chukwuma B. Duru ${ }^{3}$, Patricia N. Aniebue ${ }^{1}$, \\ Uzochukwu U. Aniebue ${ }^{4}$, Chigozie O. Ifeadike ${ }^{5}$ \\ ${ }^{1}$ Department of Community Medicine, University of Nigeria Teaching Hospital, Ituku-Ozalla, Enugu State, Nigeria \\ ${ }^{2}$ Department of HIV Care and Department of Community Medicine, Nnamdi Azikiwe University Teaching Hospital (NAUTH), Nnewi, \\ Nigeria \\ ${ }^{3}$ Department of Community Medicine, Imo State University / University Teaching Hospital Orlu, Nigeria \\ ${ }^{4}$ Department of Obstetrics and Gynaecology, University of Nigeria Teaching Hospital, Ituku-Ozalla, Enugu State, Nigeria \\ ${ }^{5}$ Department of Community Medicine, Nnamdi Azikiwe University / University Teaching Hospital (NAU / NAUTH), Nnewi, Nigeria
}

\section{Email address:}

nnebnons@yahoo.com (C. C. Nnebue)

\section{To cite this article:}

Chuka C. Agunwa, Chinomnso C. Nnebue, Chukwuma B. Duru, Patricia N. Aniebue, Uzochukwu U. Aniebue, Chigozie O. Ifeadike. Knowledge of Obstetric Danger Signs Among Women of Reproductive Age in Rural Communities in Enugu State, Nigeria. American Journal of Health Research. Vol. 3, No. 6, 2015, pp. 376-380. doi: 10.11648/j.ajhr.20150306.20

\begin{abstract}
Background: Lack of knowledge of obstetric danger signs, resulting in inability to recognize and probably react to the needs for accessing quality health care remains a major cause of preventable maternal deaths. Objective: To determine the knowledge of obstetric danger signs and its determinants amongst women of reproductive age in rural communities in Nigeria. Materials and methods: A total of 602 women of child bearing age were studied. Data collection employed a pretested, selfadministered structured questionnaire and was analysed using statistical package for social sciences version 17 . Bivariate analysis was done to identify factors associated with good levels of knowledge of danger signs. Logistic regression was used to identify determinants of a high knowledge score among women. A p value of $<0.05$ was considered significant. Results were presented in tables and summary indices. Results: Majority of respondents had a poor level of knowledge of obstetric danger signs 286(47.5\%). The most mentioned symptom was vaginal bleeding; 358(59.5\%). Factors associated with knowledge of obstetric danger signs include: age $(p=0.000)$, marital status $(p=0.000)$, educational level attained $(p=0.049)$ and parity $(\mathrm{p}=0.000)$. Attaining tertiary level of education (OR: 3.906), teaching profession (OR: 15.104) self-employed business engagement (OR: 16.144) and a high level of knowledge of disease causation (OR: 3.336) were predictors of the level of knowledge of danger signs among them. Conclusion: We recommend that effective and sustained health education and behavioral change programs with high local content be instituted in our rural communities.
\end{abstract}

Keywords: Enugu, Obstetric Danger Signs, Rural Women, Knowledge, Predictors

\section{Introduction}

Every year more than 200 million women globally become pregnant and some $10 \%$ of them are likely to develop complications that will require skilled obstetric care to prevent death or serious ill health [1]. It has also been documented that each day some 14,000 women and girls lose their lives to complications from pregnancy and childbirth [2]. This picture is further worsened by the fact that about $99 \%$ of the causes of maternal mortality in the developing countries are preventable $[1,2]$. The maternal mortality ratio in Nigeria is one of the highest in the West African subregion and despite efforts which have been made to reduce it women are still dying from pregnancy related causes [3].

Maternal deaths are strongly linked in terms of place of deaths and the four 'delays' associated with health care delivery- the delay in recognizing danger signs, the delay in deciding to seek care, the delay in reaching care and the delay in receiving care $[4,5]$. In many situations, not getting to the health facility early enough is mainly due to the inability of the woman and family members in recognizing 
symptoms and signs of a life threatening condition [6]. Even when most of the causes of these deaths are either preventable or treatable, it is sad to note that the maternal mortality ratio in Nigeria have shown only marginal reductions in the last ten years, from 704 deaths per 100,000 livebirths to 545 deaths per 100,000 livebirths, such that even as we look beyond 2015 towards the Sustainable Development Goals (SDGs), this picture ab initio defeats the attainment of the Millennium Development Goals (MDGs) targets related to maternal health [7].

In recent decades, many strategies have been implemented in an attempt to improve maternal health outcomes around the world [4].The basic objectives of focused antenatal care for instance are to detect and manage symptomatic and even symptomless but potentially serious complications of pregnancy, and to meet the pregnant woman's need for information, advice and reassurance [8]. However, people need to understand the danger signs and symptoms of these complications of pregnancy, to enable them seek care appropriately and promptly [9].

A 2010 study by Hailu et al., on the knowledge of danger signs of pregnancy by women of reproductive age in Ethiopia concludes that early identification of these danger signs are key to the survival of women in whom these causes of mortality occur [10]. When there is imbalance between the demand and the supply sides of barriers to maternal health care services, demand barriers such as lack of knowledge and awareness of obstetric danger signs may compound the effects of supply barriers via inability to recognize and probably react to the needs for accessing quality health care. Kabakyenga et al., in an assessment of the knowledge of danger signs of pregnancy and birth preparedness practices among rural women in Uganda concurred that all women should be made aware of the danger signs of pregnancy, childbirth and the puerperium so as to empower them and their families to take prompt decisions to seek health care [11].

Effective increase in the knowledge of obstetric danger signs among women through facility and community -based behavioral change strategies which include educational and community mobilization strategies when properly implemented, will influence their ability to seek help early [12]. An assessment of the level of knowledge of obstetric danger signs among rural women will identify the gaps in knowledge and form the basis for putting in place appropriate and timely interventions. It is against this backdrop that this survey will determine the level of knowledge of obstetric danger signs and its determinants among rural women in Enugu Nigeria.

\section{Materials and Methods}

Enugu State is one of the 36 states in Nigeria. It is an inland state situated in South-eastern Nigeria and is made up of 17 (five urban and 12 rural) Local Government Areas (LGAs). It has an area dimension of 7, $181 \mathrm{~km} 2$ and an approximate total population of $4,267,837$ people [13].

This was a community based cross-sectional descriptive study carried out in May 2012. The study population comprised women of reproductive age who reside in rural communities of Enugu State. Only females aged $15-49$ years who had resided for at least a year in the study area irrespective of their marital status and parity were included in the study. Women who declined consent were excluded.

In a previous study in Uganda among similar population, level of knowledge of obstetric danger signs (p) was $52.0 \%$ [11]. Therefore, $p=0.52$. The sample size was determined using the Leslie Fischer's formula for the calculation of sample size in populations greater than $10,000, n=z^{2} \mathrm{pq} / \mathrm{d}^{2}$, [14] where $\mathrm{n}=$ minimum sample size; $\mathrm{p}=$ proportion of women that knew at least one obstetric danger sign; $d=$ desired precision at $5 \% ; \mathrm{z}=$ a constant at $95 \%$ confidence interval $z=1.96$. Substituting values,

$$
\mathrm{n}=\frac{(1.96)^{2} \times 0.52 \times 0.48}{(0.05)^{2}}=383.55=384 \text { women }
$$

However, 610 questionnaires were distributed.

A multistage sampling technique was used to enrol respondents into this study.

Stage I: A simple random sampling technique was used to select one local government area (LGA), Udi out of the 12 rural LGAs in Enugu State.

Stage II: One community within the LGA (Obinagu community) was selected by simple random sampling technique.

Stage III: Systematic sampling technique was used. Within the community, the number of houses recorded under the house numbering system, 1,931 in number, was ascertained from the State headquarters of the National Population Commission. This was divided by the sample size to give a sampling interval of 5 . The index compound was then selected by simple random sampling using the balloting method and subsequently the sampling interval was used to select the next compound.

Stage IV: Then, eligible and consenting respondents within each compound were interviewed. Where there were more than one eligible woman in the compound, one was selected by simple random sampling using a ballot method.

A pretested standardized semi- structured interviewer administered questionnaire was used to obtain information on socio-demographic characteristics of the respondents and their knowledge of danger signs of pregnancy. These were administered by two trained interviewers. Data was checked at the end of each day for completeness, consistencies, outliers and missing values.

Data collected was cleaned, coded, entered and analyzed using SPSS for windows version 17 [15]. A scoring system was constructed to measure the degree of knowledge of danger signs in pregnancy among respondents using 4 categories; poor (0-2), fair (3-4), good (5-6) and very good (7-8) ranging from scores of 0 to 8 correctly mentioned danger signs. Bivariate analysis using chi square test was done to identify factors associated with good and very good levels of knowledge of danger signs. Logistic regression was used to identify determinants of a high knowledge score among women. A p 
value of $<0.05$ was considered significant. Results were presented in tables and summary indices.

Ethical approval was obtained from the Enugu State Ministry of Health Ethical Committee. Written permission to carry out this study was sought and obtained from the appropriate authorities in the community. Consent and cooperation of the respondents was solicited and obtained for the conduct and publication of this research study. All authors hereby declare that the study has therefore been performed in accordance with the ethical standards laid down in the 1964 Declaration of Helsinki.

\section{Results}

Table 1. Socio-demographic characteristics of respondents.

\begin{tabular}{|c|c|}
\hline Variable & Frequency (\%) \\
\hline \multicolumn{2}{|l|}{ Age group (years): } \\
\hline $15-19$ & $108(18.0)$ \\
\hline $20-24$ & $124(20.7)$ \\
\hline $25-29$ & $160(26.7)$ \\
\hline $30-34$ & $124(20.7)$ \\
\hline $35-39$ & $54(9.0)$ \\
\hline $40-44$ & $20(3.3)$ \\
\hline $45-49$ & $10(1.7)$ \\
\hline Mean & 27.2 \\
\hline Standard deviation & 6.66 \\
\hline Range & 35 \\
\hline \multicolumn{2}{|l|}{ ducational level: } \\
\hline None & $12(2.0)$ \\
\hline Primary & $72(12.0)$ \\
\hline Secondary & $382(63.7)$ \\
\hline Post-secondary & $134(22.4)$ \\
\hline \multicolumn{2}{|l|}{ Marital status: } \\
\hline Married & $492(82.0)$ \\
\hline Single & $104(17.3)$ \\
\hline Widowed & $4(0.7)$ \\
\hline \multicolumn{2}{|l|}{ Religion } \\
\hline Christian & $602(100.0)$ \\
\hline Muslim & $0(0.0)$ \\
\hline Others & $0(0.0)$ \\
\hline \multicolumn{2}{|l|}{ No of children } \\
\hline None & $62(10.3)$ \\
\hline $1-4$ & $450(75.0)$ \\
\hline $5-8$ & $82(13.6)$ \\
\hline $9-11$ & $8(1.2)$ \\
\hline \multicolumn{2}{|l|}{ Ever lost a pregnancy? } \\
\hline Yes & $468(77.7)$ \\
\hline No & $134(22.3)$ \\
\hline \multicolumn{2}{|l|}{ Occupation: } \\
\hline Unemployed & $314(52.7)$ \\
\hline Trader & $178(29.7)$ \\
\hline Civil servant & $94(15.7)$ \\
\hline Artisan & $8(1.3)$ \\
\hline Farmer & $2(0.3)$ \\
\hline Student & $2(0.7)$ \\
\hline Husband's Occupation & $\mathrm{N}=492$ \\
\hline Civil Servant & $148(30.1)$ \\
\hline Artisan & $168(34.1)$ \\
\hline Trader & $80(16.3)$ \\
\hline Farmer & $42(8.5)$ \\
\hline Professional eg. Doctor, Lawyer & $32(6.5)$ \\
\hline Pensioner & $26(5.3)$ \\
\hline
\end{tabular}

characteristics of respondents. Out of 610 respondents, 602 were successfully interviewed giving a response rate of $98.7 \%$. The mean and modal age groups of respondents were 27.2 years and $25-29$ years $(26.7 \%)$ respectively. Of the respondents $492(82 \%)$ were married at the time. All respondents were Christians with $382(63.7 \%)$ of them having attained secondary level of education. About 314(52.7\%) were unemployed or full time house wives while 178(29.7\%) were traders. Up to 450 (75\%) had between 1-4 children. As much as $468(77.7 \%)$ reported ever having lost a pregnancy.

Table 2 summarizes the respondents' access to Mass Media. When questioned about their access to mass media, $493(81.8 \%)$ indicated ownership of a television. An equally large number of respondents 554[92\%] also had a radio in their homes.

Table 2. Respondents access to Mass Media.

\begin{tabular}{lll}
\hline Access to mass media & Frequency & Percent \\
\hline Television & 493 & 81.8 \\
Radio & 554 & 92.0 \\
\hline
\end{tabular}

Table 3 summarizes the awareness of danger signs of pregnancy among respondents. When asked to mention danger signs during pregnancy, the most commonly mentioned symptoms were vaginal bleeding; 358(59.5\%), severe headache; 290(48.2\%) and absence of fetal movements; 282(46.8\%). The least known danger signs were breathlessness; 116(19.3\%), drainage of liquor; 166(27.6\%) and yellowness of the eyes; 43(7.1\%). All respondents mentioned at least one danger sign.

Table 3. Awareness of danger signs of pregnancy among respondents.

\begin{tabular}{lll}
\hline Danger sign in pregnancy & Frequency & Percent \\
\hline Vaginal bleeding & 358 & 59.5 \\
Drainage of liquor without labor & 166 & 27.6 \\
Severe headache & 290 & 48.2 \\
Breathlessness & 116 & 19.3 \\
Severe abdominal pain & 190 & 31.6 \\
Absence of fetal movements & 282 & 46.8 \\
EDD passed & 140 & 23.3 \\
Yellowness of eyes & 43 & 7.1 \\
\hline
\end{tabular}

Table 4 summarizes the levels of knowledge of respondents. Forty three (7.1\%) respondents had a high level of knowledge, 103(17.1\%) had good knowledge scores, $169(28 \%)$ of them had a fair level of knowledge and majority; 286(47.5\%) had a poor level of knowledge of danger signs.

Table 4. Levels of knowledge of respondents.

\begin{tabular}{lll}
\hline $\begin{array}{l}\text { Level of knowledge of danger signs } \\
\text { in pregnancy }\end{array}$ & Frequency & Percent \\
\hline Poor (0-2) & 286 & 47.5 \\
Fair (3-4) & 170 & 28.2 \\
Good (5-6) & 103 & 17.1 \\
Very Good (7-8) & 43 & 7.1 \\
\hline
\end{tabular}

Table 5 shows the factors associated with knowledge of obstetric danger signs and Predictors for knowledge of obstetric danger signs. Factors associated with knowledge of 
obstetric danger signs include: age $(\mathrm{p}=0.000)$, marital status $(p=0.000)$, educational level attained $(p=0.049)$ and parity $(p=0.000)$. Attaining tertiary level of education (OR: 3.906$)$, being a member of the teaching profession (OR: 15.104) or a self-employed business woman (OR: 16.144) as well as having a high level of knowledge of disease causation (OR: 3.336) were all identified as predictors of the level of knowledge of danger signs among the women.

Table 5. Factors associated with knowledge of danger signs and Predictors for knowledge of danger signs.

\begin{tabular}{|c|c|c|}
\hline \multicolumn{3}{|c|}{ Factors associated with knowledge of danger signs } \\
\hline Variable & $X^{2}$ & $P$ value \\
\hline Age & 96.355 & 0.000 \\
\hline Marital status & 50.293 & 0.000 \\
\hline Educational level attained & 66.795 & 0.049 \\
\hline Parity & 99.996 & 0.000 \\
\hline \multicolumn{3}{|l|}{ Predictors for knowledge of danger signs } \\
\hline Variable & $\mathrm{OR}(95 \% \mathrm{CI})$ & $P$ value \\
\hline Is not educated & $\mathrm{OR}=1$ & \\
\hline Has tertiary level of education & $\mathrm{OR}=3.906$ & 0.003 \\
\hline Is unemployed & $\mathrm{OR}=1$ & \\
\hline Is a teacher & $\mathrm{OR}=15.104$ & 0.000 \\
\hline Is a self-employed business woman & $\mathrm{OR}=16.144$ & 0.000 \\
\hline $\begin{array}{l}\text { Has a poor level of knowledge of causes of } \\
\text { disease }\end{array}$ & $\mathrm{OR}=1$ & \\
\hline $\begin{array}{l}\text { Has a high level of knowledge of causes of } \\
\text { disease }\end{array}$ & $\mathrm{OR}=3.336$ & 0.000 \\
\hline
\end{tabular}

\section{Discussion}

This survey was designed to identify the baseline level of knowledge among women in the community before the commencement of a behavioral change intervention which was aimed at correcting some misconceptions held not only by the women but also by the community in general. This study has identified not only what the level of knowledge of pregnancy danger signs are among rural women but also what factors significantly determine the level of that knowledge.

From the findings of this study, it was evident that the commonest obstetric danger sign reported by respondents was vaginal bleeding. This finding is similar to that of a study by Hailu et al., in 2010 in Southern Ethiopia where vaginal bleeding was the most commonly known danger sign among women with $49.5 \%$ of their respondents mentioning it [10]. It is also consistent with the findings of a study by the Johns Hopkins School of Public Health Program in 2004 which sought to measure the effect of a behavioral change intervention in Indonesia and reported that $30.7 \%$ and $16.7 \%$ of respondents mentioned vaginal bleeding as a danger sign in the pregnancy and post- partum periods [16]. However our finding differs from that of the study by Shobo et al., in Zaria, Northern Nigeria in 2012, where only a quarter of the women mentioned vaginal bleeding as a danger sign [17]. While it may be tempting to attribute this to geographical differences between the study populations, this variation may also be supported by the fact that levels of female education vary within Nigeria, being higher in the Southern than in the

\section{Northern part of the country.}

Less than ten percent $(7.1 \%)$ of the respondents had a high level of knowledge of obstetric danger signs, as was shown by this study. This finding is consistent with the findings of Kabakyenga et al., [11] who in a 2011 study on knowledge of danger signs in pregnancy in rural Uganda reported that only $6.9 \%$ of women had knowledge of 3 or more danger signs of pregnancy and Shobo et al., [17] in Northern Nigeria, who reported $9.9 \%$ of women with knowledge of 4 or more danger signs.

From our study, factors associated with knowledge of obstetric danger signs include: age $(\mathrm{p}=0.000)$, marital status $(p=0.000)$, educational level attained $(p=0.049)$ and parity $(\mathrm{p}=0.000)$.

This finding agrees with the findings in a study by Pembe et al., which reported that the likelihood of awareness of obstetric danger signs was increased with age, parity, when delivery was at a health institution and when the mother had been informed about complications during an antenatal visit, while attaining at least secondary education was associated with a six fold increase in awareness of obstetric danger signs [18]. Also Hailu et al., reported an association between respondents who were married and a knowledge of obstetric danger signs [10]. Shobo et al., concurred with a report of a three to four- fold likelihood of knowing four or more danger signs among women who could read English or Hausa as well as three fold likelihood of good knowledge of obstetric danger signs among respondents having children, compared to those who had no children [17]. This suggests that more exposure to pregnancy and childbirth improves the knowledge of women, probably through exposure to information at antenatal clinics and their personal exposures and experiences.

This study revealed predictors of the level of knowledge of obstetric danger signs such as attaining tertiary level of education, a high knowledge score of causation of disease as well as occupations (self- employed business and the teaching profession). These findings could be as a result of the higher levels of education in these individuals resulting in better awareness of what constituted an obstetric danger sign. However this does not explain the significant regression with business women who may be, but are not necessarily well educated.

Limitations of the study: The questionnaires were interviewer administered and this might have influenced the responses from the participants. However, in the training of research assistants it was ensured that efforts were made by these research assistants to assure respondents of confidentiality of their responses.

\section{Conclusions}

This study reveals that the commonest obstetric danger sign reported by respondents was vaginal bleeding, less than ten percent of the respondents had a high level of knowledge of obstetric of danger signs thus the number of women with a less than satisfactory knowledge of danger signs of 
pregnancy are still in the majority. Also, increasing age, marital status, educational level attained and parity were factors associated with knowledge of obstetric danger signs while predictors of the level of knowledge of obstetric danger signs include: attaining tertiary level of education, a high knowledge score of causation of disease as well as occupations (self - employed business and the teaching profession).

The implication of this finding is that most women are still likely to delay seeking healthcare in the eventuality that any of these danger signs occur and this puts them at risk of maternal morbidity and mortality. It is therefore recommended that health education and behavioral change programs be implemented within rural areas where majority of Nigerians live. Efforts should be directed towards increasing the scope of communication strategies and via local media which gets the messages directly to the women in a form they can understand and relate to.

\section{Authors' Contributions}

Author CCA was involved in the design, implementation, analysis of data and interpretation of results, author CCN was involved in the design and write up of this study, while authors CBD, PNA, UUA and COI were involved in the design and editing of the main paper. All authors read and approved the final manuscript.

\section{References}

[1] World Health Organization. Improve the quality of maternal health services. Geneva, Switzerland, WHO. Division of Reproductive Health (Technical Support), 1998; 4 (World Health Day - 7April: Safe motherhood / WHO 98.8) accessed $14^{\text {th }}$ August 2008.

[2] Donna V, Barbara K. Improving maternal health. e Journal USA: Economic perspectives, 2005; 1-7.

[3] Olumide EA, Obionu CN, Mako IV. An assessment of quality of primary health care in Nigeria. Report of a survey commissioned by the NPHCDA. Published by the NPHCDA Abuja, Nigeria. March 2000.

[4] Berg C, Danel I, Zane S, Bartlett L, eds. Strategies to reduce pregnancy- related deaths: from identification and review to action. Atlanta, Centres for Disease Control and Prevention; 2001; 45-7. In: Bullough C, Meda N, Makowiecka K, Ronsmans C, Achadi E, Hussein J. Current strategies for the reduction of maternal mortality. BJOG. 2005; 112 (9): 1180-8.

[5] Ghebrehiwet M, Morrow RM. Delay in seeking and receiving of the emergency obstetric care in Eritrea. Journal of the Eritrea Medical Association.2007; 2: 8-13.

[6] Ali YA, Malik MA, Hassan A. Comparative study of knowledge, Attitude and Practices among Antenatal Care facilities utilizing and non-utilizing women. JPak Med Assoc 2005; 55: 53.

[7] Federal Government of Nigeria, Federal Ministry of Health and National Primary Health Care Development Agency. Midwives service scheme, March 2009.

[8] National Population Commission (Nigeria) and ICF Macro Nigeria, Nigeria Demographic and Health Survey 2008. Calverton, Maryland: National Population Commission and ICF/Macro. 2009.

[9] World Health Organization. Mother- baby package: Improving safe motherhood in countries. 1994; WHO Geneva.

[10] Hailu M, Gebremariam A, Alemsged F, Knowledge about obstetric danger signs among pregnant women in Aletta Wondo district, Sidama zone, Southern Ethiopia. Ethiop J Health Sci. 2010; 20 (1): 25-32.

[11] Kabakyenga JK, Ostergren P, Turyakira E, Peterson K. Knowledge of obstetric danger signs and birth preparedness practices among women in rural Uganda. Reproductive health. 2011; 8: 33-43.

[12] Perreira KM, Bailey PE, de Bocaletti E, Hurtado E, Recinos de Villagran S, Matute J. Increasing awareness of danger signs of pregnancy through community and clinic-based education in Guatemala. Matern Child Health J. 2002; 6(1): 19-28.

[13] Learn about Enugu state, Nigeria/people, local government and ... Available online@ www.ngex.com/ Nigeria/places/states/enugu.htm. Accessed on 10/14/2015.

[14] Araoye MO. Research methodology with statistics for health and social sciences. Nathadex Publications, saw-mill, Ilorin 2nd ed. 2008: p 115-122.

[15] Statistical Package for Social Sciences (IBM SPSS) 17.0 version. United States; 2010.

[16] Suruchi S, Urvachi C, Anne P, Indra M. Published by JHPIEGO Baltimore: Johns Hopkins School of Public Health Center for Communication Program; 2004. SIAGA behavior change campaign in Indonesia impact report.

[17] Shobo GO, Yisa IO, Alawode G. Knowledge of Obstetric Danger Signs among women of reproductive age in PATHS 2 Zaria Cluster, Kaduna, Nigeria. Nigerian Journal of Medicine. 2014; 23(1); 26-32.

[18] Pembe AB, Urasa DP, Carlstedt A, Lindmark G, Nystrom L, Darj E. Rural Tanzanian Women's awareness of danger signs of obstetric complications. BMC Pregnancy and Childbirth. 2009; 26: 9-12. 